\title{
BIBLIOTECÁRIO COMO PROCURADOR INSTITUCIONAL: REFLEXÕES SOBRE ATUAÇÃO DO PROFISSIONAL DA INFORMAÇÃO EM INSTITUIÇÕES DO ENSINO SUPERIOR
}

LIBRARIAN AS INSTITUTIONAL PROSECUTOR: REFLECTIONS ABOUT THE ACTING OF INFORMATIONAL PROFESSIONALS IN HIGHER EDUCATION INSTITUTIONS

Marcos Paulo de Passosa

\begin{abstract}
RESUMO
Objetivo: Procura-se estabelecer aproximações das atribuições desenvolvidas pelo bibliotecário à do procurador institucional no contexto de atuação profissional. Metodologia: De natureza bibliográfica e abordagem qualitativa com foco no objeto em discussão e experiência do pesquisador. Resultado: As atividades de gestão e organização de documentos impressos e eletrônicos exercidas pelos bibliotecários no contexto administrativo das instituições de ensino superior requerem competências, habilidades e aptidões que permitem a este profissional ampliar e também atuar como procuradores institucionais. Conclusões: Trata-se de novo nicho profissional, alinhado às reflexões sobre o papel do profissional da informação na contemporaneidade, especialmente no contexto de atuação em instituições de ensino superior.
\end{abstract}

Descritores: Procurador Institucional. Atuação profissional do bibliotecário. Mercado de trabalho do bibliotecário.

\section{INTRODUÇÃO}

Estudos nos campos da Biblioteconomia, da Ciência da Informação e da História Social (BORKO, 1968; RAYWARD, 1997; JACOB, 2000; BURKE, 2003; MEY; SILVEIRA, 2009) mostram que desde a Antiguidade Clássica a humanidade tem criado e desenvolvido técnicas para gestão e organização da informação e do conhecimento registrado (documento).

Do ponto de vista da gestão, normas e diretrizes institucionais foram e têm sido elaboradas no bojo das condições políticas e econômicas presentes 
na sociedade; no que concerne à organização sistemática da informação e do conhecimento registrado, instrumentos como os inventários, os catálogos sistemáticos, índices remissivos e sistemas de classificação, especialmente, ocuparam e ocupam centralidade no processo de ordenação e gestão de acervos.

As perspectivas, primeira de reunião, armazenamento, preservação e conservação do repertório bibliográfico existente (Antiguidade e Idade Média) e, posteriormente, de acesso e difusão dos acervos (Modernidade), demandaram o aperfeiçoamento das instâncias administrativas e dos instrumentos no curso da história das instituições culturais e de memória: bibliotecas, arquivos, centros de documentação e museus.

A criação do Instituto Internacional de Bibliografia (IIB), em 1895, e a institucionalização da Ciência da Informação na década de 1960 como nova área de estudos e campo de pesquisa no contexto contemporâneo, podem ser tomados como marcos históricos dos processos e políticas de gestão e de organização da informação e do conhecimento registrado, bem como reflexo de mudanças que marcaram a transição do foco na produção bibliográfica para a documental, perspectiva mais ampla com relação aos objetos culturais no século XIX; do documental para o informacional no século $X X$, marcado, sobretudo, pelo advento das tecnologias computacionais e, atualmente, a criação dos avatares virtuais da documentação física, bem como a produção eletrônica autêntica, efetivamente.

Nesse movimento sócio-histórico há, notoriamente, dentre diferentes mudanças, a paradigmática: da conservação cultural para a difusão cultural, da custodial para a pós-custodial, do acervo para a informação; e de perspectivas: da guarda para fluxos exponenciais de produção, dispersão e disseminação de acesso aos conteúdos informacionais. Do ponto de vista profissional, contudo, permanece clara a atuação do bibliotecário e do documentalista no processo, condicionada aos paradigmas aos quais se inscreveram e ainda se inscrevem.

A complexidade e a ampliação das atividades próprias da contemporaneidade impôs novos desafios e foi responsável por diferentes demandas de atuação profissional em diferentes setores. Na medida em que a 
informação tem sido tomada como imperativo não apenas político e econômico, mas cultural, educativo e estratégico no contexto das instituições, sobretudo do ensino superior colocou em relevo essa nova tendência de ação.

Diante do exposto, afirma-se que o domínio ou expertise técnica do bibliotecário com relação à gestão e à organização de documentos e serviços de informação é um dos fatores que contribuem para sua inserção profissional em diferentes mercados de trabalho. Hoje em dia é possível falarmos de bibliotecários que atuam fora das bibliotecas sem que o fato cause estranhamento entre os pares; pelo contrário, é provável que desperte curiosidade e inaugure mobilizações para que outros bacharéis possam, também, adentrar novas possibilidades de atuação profissional. Nesse sentido, podemos citar casos de bibliotecários que atuam com a Gestão da Informação, Curadoria Digital, UX Researcher, E-commerce, dentre outras profissões ou áreas de atuação no século XXI.

Nessa comunicação destaco o Procurador Institucional (PI), função que tenho exercido de forma articulada com a profissão de bibliotecário no contexto de uma instituição de ensino superior privada. Cabe destacar que o PI pode exercer diferentes cargos numa mesma instituição ou realizá-lo como prestador de serviços, como por exemplo, numa consultoria que atua sobre o momento de regulação de cursos ou recredenciamento de instituições de ensino superior (IES) junto ao Ministério da Educação (MEC) e Instituto Nacional de Estudos e Pesquisas Educacionais Anísio Teixeira (INEP).

De natureza bibliográfica e abordagem qualitativa foi realizada pesquisa com foco no objeto em discussão, qual seja, reflexão sobre a atuação do bibliotecário como procurador institucional, aproximações relacionadas às atribuições e funções que desempenham no contexto das IES. Nesse sentido, foi abordada produção que trata do tema no contexto brasileiro e retomada de reflexão inicial (PASSOS, 2020; 2021) adensada nesta ocasião.

Por fim, explicita-se que os domínios e habilidades técnicas do bibliotecário com relação à gestão e à organização de documentos e serviços de informação o credibilizam para o exercício de atribuições realizadas pelo PI, além de conjugar e ampliar sua participação e atuação profissional no contexto 
do ensino superior.

Nesse sentido, vale dizer que se o bibliotecário detém um saber vinculado aos arquivos, fontes documentais, gestão e organização de documentos e serviços informacionais, o procurador institucional, por sua vez, conhece dinâmicas da gestão da vida acadêmica, da produção de conhecimento sobre aspectos institucionais, analisa e cria documentos, revisa e redige novos relatórios técnicos e processuais, dentre outros, constituindo, assim, atividades que ultrapassam o tratamento documental. Assim, a conexão e a intercambialidade entre ambas as funções permitem ao bibliotecário, antenado com a atuação como procurador institucional, concatenar o métier que domina a outra gama de saberes que o permite adentrar em diferentes instâncias da instituição, com uma atuação protagonista.

Diante do exposto, o profissional atuará junto da gestão acadêmica (direção geral e do núcleo docente estruturante dos cursos) de forma estratégica, aspecto que aproxima, explicita e redimensiona as atividades de ensino, de pesquisa e extensão articuladas às atividades presentes no âmbito da biblioteca universitária, além de redefinir a posição de prioridades no conjunto de ações previstas e da política institucional presente no Plano de Desenvolvimento Institucional (PDI), nos Projetos Pedagógicos dos Cursos (PPC) e da própria instituição de ensino superior a qual se vincula.

\section{MUDANÇAS NOS PROCESSOS DE AVALIAÇÃO DAS IES NO BRASIL}

Nos anos 2000, no bojo das muitas mudanças ocorridas no Ensino Superior do Brasil, principalmente relacionadas à forma e aos instrumentos utilizados para realização do censo da educação superior, bem como a dinamização dos processos de avaliação, regulação e supervisão das instituições de ensino superior (IES), o Ministério da Educação adotou algumas medidas rumo à informatização de suas atividades. Dentre estas medidas Medeiros (2015) e Souza et al. (2015) destacam como iniciativas: 
- (2000) Implantação do SIEd-Sup, que solicitava para cada instituição a indicação de profissional adequado para acompanhar todos os dados da Mantenedora;

- (2001) Designação de um Pesquisador Institucional para ser interlocutor e responsável pelas informações da IES junto ao INEP para responder anualmente ao Censo da Educação Superior no SIEd-Sup;

- (2002) Implantação do Sistema de Acompanhamento de Processos das Instituições de Ensino Superior (SAPIEns), pelo MEC;

- (2004) Criação do Sistema Nacional de Avaliação da Educação Superior (SINAES);

- (2005) Designação do Pesquisador Institucional como responsável pela coleta de dados e preenchimento do questionário eletrônico do Censo da Educação Superior;

- (2007) Implantação do e-MEC - Fluxo de Processos de regulação;

- (2007) Designação do Procurador Educacional Institucional (PI) como responsável pela abertura, instrução, acompanhamento dos processos de regulação nesse sistema.

Diante do exposto, podem ser destacadas a criação do Sistema Nacional de Avaliação da Educação Superior (SINAES) em 2004 (BRASIL, 2004), a implementação do sistema e-MEC - Fluxo de Processos de regulação das IES em 2007 (BRASIL, 2007) e a institucionalização do cargo de Procurador Educacional Institucional, comentados adiante.

\subsection{Contextualização sobre o SinAeS, o Sistema e-MEC e Atuação do Procurador INSTITUCIONAL}

O SINAES trouxe um caráter sistemático ao processo de avaliação institucional da Educação Superior. Constituído por três componentes principais (avaliação das IES e avaliação dos cursos e do desempenho dos 
estudantes) possui instrumentos complementares como a autoavaliação, realizada pela comissão própria de avaliação (CPA), a avaliação externa, como as visitas in loco realizadas por comissão designada pelo MEC para avaliação dos cursos de graduação, dentre outros instrumentos, como por exemplo, o Censo da Educação Superior e o Exame Nacional de Desempenho de Estudantes (ENADE).

Para operacionalização dos processos, a plataforma e-MEC, sistema eletrônico para o fluxo de trabalho, gestão e gerenciamento de informações, permite o acompanhamento das documentações protocoladas e acesso no sistema às portarias e os processos de credenciamento ou recredenciamento institucional, pedidos de autorização para abertura de cursos e ofertas de vagas para graduação e pós-graduação, solicitação de reconhecimento de cursos e de renovação de reconhecimento de cursos. Também, permite acompanhar processos de aplicação e/ou revogação de medidas cautelares impostas pelas comissões do MEC no percurso de avaliação dos cursos em andamento, bem como o acesso ao conteúdo das diligências instauradas com relação aos processos encaminhados e ao envio de outras documentações relacionadas aos processos tramitados que permaneceram em análise para fins de regulação, com prazos específicos para tramitações complementares.

A utilização do sistema eletrônico e-MEC demanda atividades de gestão e de organização que garantem o acompanhamento e a supervisão das instituições cadastradas para ofertar a educação em nível superior. Sua criação impulsionou a presença de um profissional que realizasse a interlocução entre as IES e o MEC: o Procurador Institucional.

O Procurador institucional (PI) é um profissional que atua como interlocutor nos processos de avaliação, regulação e supervisão do ensino superior das IES através da tramitação de documentos institucionais de natureza acadêmica e administrativa, tais como o Plano de Desenvolvimento Institucional (PDI), os Projetos Pedagógicos de Cursos (PPC), o Regimento e o Estatuto das mantenedoras, a Situação Legal, o Balanço Financeiro, dentre outros. 
A Portaria 21/2017 estabeleceu o papel do PI nas IES do país. Trata-se de função desginada/nomeada pelo Representante Legal $(R L)$ da mantenedora e deve atuar junto ao Dirigente Legal (DL), diretor nas instituições privadas ou reitor, nas públicas, que, nos termos da legislação civil e administrativa, responderá pelos atos praticados pelo $\mathrm{Pl}$, bem como pela veracidade $\mathrm{e}$ legalidade das informações de caráter declaratório inseridas no sistema, com a finalidade de que a comunicação com os órgãos do MEC considere as políticas, os procedimentos e os dados da instituição no seu conjunto $\left(\S 1^{\circ}\right.$ e $\S$ $2^{\circ}$ da Portaria 21/2017). Conforme indicado no Art. 16 da mesma lei, o PI

[...] será responsável por prestar as informações no sistema eMEC, relativas às atualizações cadastrais e à tramitação de processos regulatórios vinculados às respectivas instituições, bem como pelos elementos de avaliação, incluídas as informações necessárias à realização do Exame Nacional de Desempenho de Estudantes ENADE (BRASIL, 2017, p. 30).

No artigo 15 da legislação específica, consta que o PI poderá indicar Auxiliares Institucionais (Al) para compartilhar tarefas originalmente sob sua responsabilidade. Nesse sentido, podem ser nomeados os coordenadores de cursos que responderão às diligências instauradas nos processos regulatórios, elaboração de recursos, a impugnação de relatórios avaliativos do INEP, arquivamento de processos e envio de respostas no formulário eletrônico presentes internamente no sistema e-MEC. Nessa perspectiva a legislação deixa claro que "as informações prestadas pelo PI e pelos Al presumem-se válidas, para todos os efeitos legais" ( $§ 1^{0}$ da Portaria 21/2017).

Por fim, no Art.16, a lei especifica que o RL da mantenedora e o PI por ele designado são responsáveis pelo acompanhamento da exatidão e fidedignidade das informações prestadas no Sistema e no Cadastro e-MEC atinentes à respectiva IES e por mantê-las atualizadas (BRASIL, 2017).

Em suma, o PI tem papel fundamental nas decisões estratégicas da instituição: a decisão de criar um curso novo, aumentar vagas, modificar projeto pedagógico de curso, revisar políticas acadêmicas, amparadas no conhecimento da legislação, tais como: Lei de Diretrizes e Bases (LDB) - Lei 9.394/96; Lei no 10.861/2004, que institui o Sistema Nacional de Avaliação da Educação Superior - SINAES; Decreto ํo 9.235/2017 (funcionamento do 
ensino superior de modo geral); Decreto o 9.057/2017 (funcionamento da educação a distância), dentre outras.

\section{O PROFISSIONAL DA INFORMAÇÃO NO SÉCULO XXI}

No início dos anos 1990 a ordem social, política e econômica impulsionada pela Globalização, pela forte competitividade das coporações e indústrias, os avanços tecnológicos que dinamizaram a comunicação via rede e a ruptura das barreiras territoriais e distanciamentos geográficos, provocaram aumento exponencial de produtos técnico-científicos, patentes, dentre outros, e forjaram novos mercados e formas de atuação profissional no mundo.

Diante do panorama que se desenhava, novas profissões surgiram, outras tiveram suas demandas diminuídas ou se extinguiram completamente, outras foram redefinidas em termos de perspectivas de atuação e foram pressionadas a uma adequação/adaptação e atualização em termos de competências e de "funcionalidade" para não serem, também, questionadas quanto sua relevância nesse novo cenário.

No bojo dessas transformações o "profissional da informação" começava a ser definido conceitualmente e relacionado a diferentes nichos de atuação. Assim, administradores, arquivistas, analistas de sistemas, analistas de dados, bibliotecários, museólogos, jornalistas passaram a ser observados dentro de um rol de papeis profissionais que interessariam ao mercado e indústrias da informação, sendo considerados também objeto de análise e de estudo no campo da Ciência da Informação, do ponto de vista teórico e também das práticas, uma vez que atuam diretamente com fluxos, gestão e organização de dados e serviços de informação de natureza administrativa, sigilosa ou pública, no contexto de diferentes instituições, desde as culturais e educativas até as industriais, empresariais e governamentais.

Conforme apontado por Guimarães (1997) essa efervescência e multiplicidade de caminhos e opções ensejou a criação do SIG/MIP (Special Interest Group / Modern Informational Professional) em 1992 pela Federação Internacional de Informação e de Documentação (FID). Desde então, a literatura da área têm apontado para novos mercados e posturas pertinentes ao 
profissional da informação. Aspectos como flexibilidade, inovação, imaginação e criatividade caracterizariam esse profissional a contrapelo de uma função desempenhada de forma reduzida e operacional para atuar no conjunto de reflexões, tomadas de decisão, redefinição de estratégias e planos de trabalho de gestão.

Em diálogo com Ponjuan Dante (1993), Guimarães (1997, p. 128) apontava ainda que um profissional especializado, organizado, investigador, responsável, laborioso e orientado para o cliente, com aptidões para realização de atividades associativas, possuiria características qualificadoras para atuação nesse novo cenário e mercado da informação.

O autor apontava que o "Moderno Profissional da Informação" teria sua atuação centrada em algumas linhas básicas de ação, quais sejam, a Gerência de Unidades e Sistemas de Informação, o Tratamento da Informação e a Ação Social (GUIMARÃES, 1997).

Nessa perspectiva, segundo o autor, o profissional assumiria a posição de manager numa instituição com foco na racionalização dos procedimentos (e gastos), compartilhamento de recursos, estabelecimento de parcerias e integração das unidades de informação em redes ou sistemas mais amplos; no que concerne o segundo ponto, o tratamento documentário e da informação em si: reunir, organizar e dispor; por fim, a responsabilidade civil implicada na difusão ética, confidencial e cidadã com conteúdos informacionais para a sociedade (GUIMARÃES, 1997).

Em suma, a mobilização da FID colocava em perspectiva a participação e atuação mais ativa dos profissionais da informação no contexto das instituições às quais se vinculariam. Sob essa base reflexiva pensamos a atuação do bibliotecário como procurador institucional no contexto das instituições de ensino superior.

\subsection{Bibliotecário e Procurador Institucional: Características Específicas, Aproximações e Perspectivas de Atuação}

Estudos de Arantes (2013), Medeiros (2015), Sousa et al. (2015) destacam aptidões, competências, habilidades e/ou conhecimentos 
fundamentais ao PI. Os autores indicam, por exemplo, os seguintes aspectos: aptidão para analisar dados e indicadores qualitativos e quantitativos; aptidão para lidar com sistemas de informática e discernimento para identificar problemas que são oriundos do sistema eletrônico e-MEC, da Internet ou do seu próprio sistema interno da IES; conhecimento sobre os instrumentos utilizados nas avaliações de cursos e de instituições pelo MEC; habilidades para produção de textos técnicos, material didático e trabalhos de pesquisa com objetivo de orientar pessoas de diferentes graus na instituição para coleta de dados, gestão e tramitação de documentos em formato físico e eletrônico que serão analisados nos processos avaliativos.

Com relação aos processos avaliativos das bibliotecas universitárias, cuja responsabilidade recai sobre a gestão do bibliotecário, os instrumentos utilizados pelo INEP/MEC dão ênfase para a apresentação de indicadores sobre a presença nos acervos físicos ou digitais de bibliografia básica e complementar indicadas nos planos de ensino das disciplinas, bem como 0 acesso; relatórios de gerenciamento e listagens de circulação de materiais em empréstimo e número de consulentes; produtos e serviços variados, infraestrutura adequada para acomodações e ambientes para funcionários e usuários da biblioteca (INEP, 2018).

Contudo, se este conjunto acima mostra-se suficiente para fins de regulação da IES perante o MEC, no contexto das bibliotecas universitárias, vale recuperarmos em Le Coadic (1996) e Valentim (2002) alguns aspectos e atributos da qualificação profissional do bibliotecário, uma vez que procura-se estabelecer equivalência da atuação profissional em ambas as funções de gestão e organizacionais e de serviços de informação no contexto das instituições de ensino superior.

Na primeira edição de sua obra referencial Le Coadic (1996, p. 106) apontava alguns aspectos presentes nas atribuições do profissional da informação. Segundo o autor, os profissionais da informação "adquirem informação registrada em diferentes suportes, organizam, descrevem, indexam, armazenam, recuperam e distribuem essa informação em sua forma original ou como produtos elaborados a partir dela". Além disso, processam a informação 
recorrente às técnicas eletrônicas de informação que utilizam os computadores e as redes de telecomunicação.

Para a autora, quatro categorias são tidas como esperadas do profissional bibliotecário no quadro da sociedade da informação: as competências de comunicação e expressão, as técnico-científicas, as gerenciais, as sociais e políticas (VALENTIM, 2002).

As categorias e aspectos aventados pelos autores merecem destaque com relação à atuação do bibliotecário no que implica especificidades do fazer do procurador institucional:

- a primeira, devido à análise, redação e elaboração de relatórios técnicos e processuais presentes no processo de regulação da IES; - a segunda, relacionada ao processamento técnico de documentos e serviços de informação tais como a seleção, registro, armazenamento e preservação de documentos, à recuperação e disseminação em qualquer suporte tramitado - em formato eletrônico - com os órgãos reguladores da Educação no Ensino Superior (INEP/MEC) via plataforma e-MEC; em formato impresso, quando da visita in loco para fins de regulação ou de supervisão instaurados por processos de diligências;

- a terceira, relacionadas ao planejamento, organização, avaliação de sistemas, produtos e serviços informacionais, que requer a participação do profissional em diferentes setores no contexto das instituições de ensino superior junto ao acadêmico (direção, coordenação e núcleo docente estruturante), ao administrativo (secretaria, departamento financeiro) e, também, relacionados à infraestrutura (bibliotecas, laboratórios de ciências ou informatizados, dentre outros);

- por fim, a quarta prima pela fidedignidade e compromisso com a comunidade acadêmica (corpo docente, corpo discente, técnicosadministrativo) e comunidade local, pois implica confiabilidade, senso ético e responsabilidade social com as políticas de ensino e de formação propostos pela instituição. 
Conforme 0 exposto, tais aspectos explicitam proximidades $\mathrm{e}$ semelhanças da atuação do bibliotecário com atividades realizadas pelo Procurador Institucional no contexto das IES.

À guisa de uma reflexão inicial podemos formular algumas ponderações:

Perante as diretrizes que regem a profissão ${ }^{1}$ não seria o caso de os bibliotecários terem reconhecidas entre suas qualificações/habilidades administrativas e operacionais, também, as funções realizadas pelo $\mathrm{PI}$, uma vez que caracterizaria oportunidade para uma maior participação deste profissional no contexto acadêmico, bem como dos processos de regulação institucional?

Compreendido que as noções concernentes à gestão $e$ ao armazenamento documentais, serviços de informação tais como a recuperação e a transmissão de documentos em formato eletrônico, bem como a sistematização de processos organizacionais, de diferentes naturezas, mantêm proximidade e correlação com as atribuições e domínios técnicoadministrativos realizados pelos procuradores institucionais, não seriam estes aspectos condicionantes para que bibliotecários atuassem, também, nesse segmento de mercado?

Sem a pretensão de encerrar o assunto, ficam lançadas essas questões para o campo de atuação profissional do bibliotecário no contexto das bibliotecas universitárias.

\section{CONSIDERAÇÕES FINAIS}

No contexto das instituições de ensino superior a função de bibliotecário articulada à de procurador institucional permite uma visão ampla dos aspectos presentes nos processos de regulação, bem como articulação das demandas da biblioteca com o departamento acadêmico (direção geral, coordenação de cursos e secretaria acadêmica). Muitas vezes, essa relação é marcada por

\footnotetext{
1 Podemos citar como exemplo os Artigos 6 da LEI № 4.084, DE 30 DE JUNHO DE 1962, que dispõe sôbre a profissão de bibliotecário e regula seu exercício. Também, alguns pontos constantes na descrição sumária de atividades especificadas no sistema de Classificação Brasileira de Ocupações (CBO).
} 
uma certa dificuldade de diálogo sobre a natureza das prioridades institucionais. A melhoria desse diálogo pode se tornar um processo de facilitação tanto para a visibilidade dos serviços prestados pelos bibliotecários na instituição quanto para redefinir posição de prioridade da biblioteca no conjunto de ações previstas no Plano de Desenvolvimento Institucional (PDI), nos Projetos Pedagógicos dos Cursos (PPC) e na própria instituição.

Vale acrescentar que devido à pandemia provocada e disseminada em nível mundial pela Sars-Cov-2 (Covid-19) nos anos de 2020 e 2021, foram realizadas modificações nas formas avaliativas do INEP/MEC. Atualmente, com a publicação da Portaria no 165, de 20 de abril de 2021 (BRASIL, 2021), foi instituída a avaliação externa virtual in loco. No bojo das alterações ocasionadas, as bibliotecas virtuais assumiram papel central pois seus serviços e produtos passaram a ser imprescindíveis à comunidade acadêmica.

Ademais, vale frisar que a importância da fisicalidade institucional da Biblioteca, das suas coleções, dos profissionais que ali atuam, remontam não apenas à uma tradição secular em torno do patrimônio cultural bibliográfico registrado (documentado), selecionado, organizado e difundido, mas à sociabilidade que permite trocas intelectuais e provocadoras nos processos de pesquisas e estudos para a construção de novos conhecimentos e "relações com o saber" (CHARLOT, 2000).

Por fim, vale ressaltar que muitas vezes o profissional que realiza 0 trabalho como PI nas instituições privadas é egresso de áreas de natureza administrativa ou tecnológica, sendo os administradores, pedagogos e gerentes de tecnologia da informação os mais recorrentes. Longe de incutir problematizações acerca da qualificação técnica de outros profissionais que exercem a função de procurador institucional nas e para as IES, nem abandonar nichos tradicionais nos quais atuamos, esta reflexão, que advém de uma experiência particular, pretende ampliar possibilidades de percepção de mercado e de atuação do profissional bibliotecário - profissional da informação - no contexto das instituições de ensino superior, em consonância às premissas e demandas próprias de um mercado novo, demandado e forjado no contexto sócio-econômico da chamada Sociedade da Informação. 


\section{REFERÊNCIAS}

ARANTES, M. P. C. In: WORKSHOP ABMES - TREINAMENTO DO PROCURADOR INSTITUCIONAL, 1. Procurador Institucional: perfil, papel e atuação nas IES. 2013. Extensão MP3. [S.I.]: ABMES, 2013.

BORKO, H. Information Science: What is it?. American Documentation, v. 19, n. 1, p. 3-5, jan. 1968.

BRASIL. Ministério da Educação. Portaria normativa no 21, de 21 de dezembro de 2017. Diário Oficial da União, Brasília, DF, 22 de dezembro de 2017. Seção 1. p. 18-31.

BRASIL. Lei no 10.861, de 14 de abril de 2004. Institui o Sistema Nacional de Avaliação da Educação Superior - SINAES e dá outras providências. Brasília, DF, 2004.

BRASIL. Ministério da Educação. Portaria normativa no 40, de 12 de dezembro de 2007. Diário Oficial da União, Brasília, DF, 29 de dezembro de 2010. Seção 1. p. 23-31.

BRASIL. Ministério da Educação. Portaria no 165, de 20 de abril de 2021. Diário Oficial da União, Brasília, DF, 22 de abril de 2021. Seção 1. p. 181.

BURKE, P. Uma histórial social do conhecimento I: de Gutenberg a Diderot. Rio de Janeiro: Zahar, 2003.

CHARLOT, B. Da relação com o saber: elementos para uma teoria. Porto Alegre: Artmed, 2000.

GUIMARÃES, J. A. C. Moderno profissional da informação: elementos para sua formação no Brasil. Transinformação, Campinas, v. 9, n. 1, p. 124-140, jan./jun. 1997. Disponível em: https://brapci.inf.br/index.php/res/v/21356. Acesso em: 10 out. 2021.

INSTITUTO NACIONAL DE ESTUDOS E PESQUISAS EDUCACIONAIS ANÍSIO TEIXEIRA (INEP). Avaliação in loco e novos instrumentos de avaliação de instituições de educação e cursos de graduação: subsídios para a atuação de procuradores institucionais (PI). Brasília, DF: INEP/MEC, 2018.

JACOB, C. Ler para escrever: navegações alexandrinas. In: BARATIN, M.; JACOB, C. (dir.). O poder das bibliotecas: a memória dos livros no Ocidente. Rio de Janeiro: Ed. UFRJ, 2000. p. 45-73.

LE COADIC, Y. A Ciência da Informação. Brasília: Briquet de Lemos, 1996.

MEDEIROS, I. Procurador Institucional: um papel estratégico para instituições de ensino superior. Periódico Científico Projeção e Docência, Brasília, v. 6, 
n. 2, p. 38-46, 2015. Disponível em:

http://revista.faculdadeprojecao.edu.br/index.php/Projecao3/article/view/552.

Acesso em: 10 out. 2021.

MEY, E. S. A.; SILVEIRA, N. C. Breve história dos catálogos e da catalogação. In: MEY, E. S. A.; SILVEIRA, N. C (org.). Catalogação no plural. Brasília: Briquet de Lemos, 2009. p. 59-93.

PASSOS, M. P. Perspectivas e possibilidades para a atuação profissional do bibliotecário em instituições do ensino superior privado como Procurador Institucional. BOB News @ Expresso CRB-8, São Paulo, v. 51, set. 2020. Disponível em: https://crb8.org.br/wp-content/uploads/2021/09/BOBNEWS@Expresso-Numero-51-Agosto-e-Setembro-2020.pdf. Acesso em: 26 jun. 2021.

PASSOS, M. P. Bibliotecário como Procurador Institucional: gestão e organização de documentos em instituições do ensino superior. In: COLÓQUIO EM ORGANIZAÇÃO, ACESSO E APROPRIAÇÃO DA INFORMAÇÃO E DO CONHECIMENTO (COAIC), 5., 2021, Londrina. Anais [...]. Londrina: UEL, 2021. p. 18-29. Disponível em:

http://www.uel.br/eventos/cinf/index.php/coaic2021/coaic2021/paper/view/675. Acesso em: 22 ago. 2021.

PASSOS, M. P. Os infortúnios e deleites vividos por um inseto bibliotecário. INFOhome, fev. 2021, Biblioteca pelo avesso. Disponível em: http://www.ofaj.com.br/colunas_conteudo.php?cod=1275. Acesso em: 13 out. 2021.

PONJUAN DANTE, G. Does the Modern Informational Professional have a life cycle? FID News Bulletin, v. 43, n. 3, p. 61, mar.

RAYWARD, W. B. The origins of information science and the International Institute of Bibliography/Internatinal Federation for Information and Documentation (FID). Journal of the American Society for Information Science, New York, v. 48, n. 4, p. 289-300, apr. 1997.

SOUSA, D. B.; SOUSA, M. K.; SOUSA, M. P.; MENEZES, L. A. Dilemas e Desafios da Função do Procurador Educacional Institucional. In: ENCONTRO DE PESQUISA E EXTENSÃO DA FACULDADE LUCIANO FEIJÃO, 8., 2015, Sobral. Anais [...]. Sobral: Faculdade Luciano Feijão, 2015.

VALENTIM, M. L. P. Formação: competências e habilidades do profissional da informação. In: VALENTIM, M. L. P. (org.). Formação do profissional da informação. São Paulo: Polis, 2002. p. 117-132.

\section{LIBRARIAN AS INSTITUTIONAL PROSECUTOR: REFLECTIONS ABOUT THE ACTING OF}




\title{
INFORMATIONAL PROFESSIONALS IN HIGHER EDUCATION INSTITUTIONS
}

\begin{abstract}
Objective: The article aims to establish similarities between attributions developed by librarians and institutional prosecutors. Method: Bibliographic research and qualitative approach with focus on the object in discussion and on the researcher experience. Result: The management and organization activities of printed/electronic documents made by the librarian on administrative context of higher education institutions require competences, skills and abilities which allow this professional to expand and also act as institutional prosecutor. Conclusions: It's a new professional niche, aligned with the reflections about the informational professional role nowadays, specially in higher education institutions.
\end{abstract}

Descriptors: Institutional Prosecutor. Librarian professional acting. Librarian job market.

\section{EL BIBLIOTECARIO COMO PROCURADOR INSTITUCIONAL: REFLEXIONES SOBRE LA ACTUACIÓN DEL PROFESIONAL DE LA INFORMACIÓN EN LAS INSTITUCIONES DE ENSEÑANZA SUPERIOR}

\begin{abstract}
Resumen:
Objetivo: Buscase establecer aproximaciones de las atribuciones desarrolladas por el bibliotecario a del procurador institucional en el contexto de la actuación profesional. Metodología: De naturaleza bibliográfica y abordaje cualitativo con foco en el objeto en discusión y la experiencia del investigador. Resultados: Las actividades de gestión y organización de documentos impresos y electrónicos ejercidas por los bibliotecarios en el contexto administrativo de las instituciones de enseñanza superior requieren de competencias, habilidades y aptitudes que permiten a este profesional ampliar y también actuar como procuradores institucionales. Conclusiones: Se trata de un nuevo nicho profesional, alineado a las reflexiones sobre el papel del profesional de la información en la contemporaneidad, especialmente en el contexto de la actuación en las instituciones de enseñanza superior.
\end{abstract}

Descriptores: Procurador institucional. Actuación profesional del bibliotecario. Mercado de trabajo del bibliotecario.

Recebido em: 14.10 .2021

Aceito em: 27.12.2021 